\title{
Evaluation of corporate success using synergistic CPA and CPR corporate citizenship
}

\author{
Michael Taillard \\ Central Michigan University, Michigan, USA \\ Miroslav Mitrović \\ Strategic Research Institute, Beograde, Serbia
}

\begin{abstract}
Corporate Political Activities (CPA) and Corporate Public Relations (CPR) are both non-market communication strategies that effect market positioning, brand strength and the business success of a company. In this study, the use of CPA and CPR by several companies are analyzed based on their economic and brand strength metrics, which confirms the hypothesis that use of these strategies has a positive impact on their market position and brand stability. Using the Multi-Value Comparative Quality Analysis (mvCQA), the research strives to measure the synergistic influence of CPA and CPR on a company's performance. Building on the existing literature for the uses and implementation of mvCQA, this research reinforces the role mvCQA plays in delivering quality and comparative findings of correlation between CPR and CPA toward market strength. This study confirms that the synergy between CPR and CPA improves corporate strategic development. It is inferred that CPR and CPA maintain non-linear correlation with industry and market niches, specific cultural and business environments, as well as overall corporate strategy goals.
\end{abstract}

\section{Keywords}

strategic communication, corporative political activity, corporative social responsibility, lobbying, Comparative Quality Analyses (CQA), Multiple Variable Model.

\section{Introduction}

The use of strategic corporate management to develop the methods needed to achieve or expand the specific goals of a corporation's success, necessitates the application of an integrated strategic communications (Mitrović, 2019). The modern globalized business environment is complex with dynamic set of factors including but not exclusive to political, economy, business, ethic, and other social science multidisciplinary interaction that can influence the success or failure of a corporation. The contemporary strategies of corporate communication has evolved quite a bit from its origins in the works of the "Father of PR", Edward Bernays (Bernays, 1928 , 1951). Furthermore, the complexity of the business environment indicates that a comprehensive communications strategy, utilizing analytical and project-based approaches to the planning and implementation of applied PR in the management context is a vital necessity to addressing each target audience. When viewed conjunctively, this illustrates that the contemporary theory behind strategic management; which in self-compiling theories of relationship, cognition, behavior, and mass communication; strongly relate to organizational culture.

A review of scholarly literature by Oliver (Oliver, 2007), details that there are three main scopes of research into this field of study: 1) Business and political communication strategy, which includes both public and government affairs which shapes corporate reputation and influence over external operating environment; 2) 
Governance and leadership communication strategy involving employees, managers, directors, and shareholders; and 3) Integrated marketing communication strategy. In this article, the roles of corporate public relations (CPR) and corporate political activity (CPA) are analyzed through their produced synergistic effects specifically within non-market strategies that are used to support overall corporate success. This is only a part of the total public communications strategy, supporting a comprehensive corporate strategic management, through which CPR and CPA are analyzed using comparative quality analysis (CQA) (Taillard, 2014). The findings in this analysis are elaborated upon in the form of conclusion wherein CPR and CPA contributions are recognized as conditions for sustainable brand development. Alone, these things have little longterm positive returns, but by implementing a cohesive strategy that incorporates both active engagement in lobbying/policymaking and in public perceptions of active community involvement the data indicates better overall performance.

\section{CPR and CPA: overall corporate strategic support}

The contemporary business environment is recognized as complex system that consists of both market and non-market components (Baron, 1995; Boddewyn, 2003; Doh, Lawton, \& Rajwani, 2012). At first glance, CPR and CPA are different business functions, but when used in conjunction they have synergistic effects on an organization's efficiency and competitive advantages (Taillard, 2013). The business environment of today includes not just basic economic principles but also contain social and political roles for each company, regardless of whether they are included in the plans of the company (Donaldson \& Preston, 1995; Wicks, Gilbert, \& Freeman, 1994). An organizations' corporate public relations (CPR) and corporate political activity (CPA), as part of non-market strategies, tend to contribute to a corporate advantage in communication toward a wide public audience that can shape ideas, opinions, beliefs, cultural associations, and public policy; proactively shaping the external environment (Taillard, 2013). Each of these public factors are directly or indirectly influential on corporate activities. An organization's CPR and CPA can significantly contribute toward improving a firm's public position and overall company strength
(Bonardi, Holburn \& Bergh, 2006; Lawton, Mcguire, \& Rajwani, 2012; Schuler, Rehbein, \& Cramer, 2002). More closely, an organization's use of CPR and CPA is recognized as a form of nonverbal communication strategy expressed through other methods such as those described in signal theory, through imagery and actions, with the aim to facilitate the development of the trust between company and policymakers: mostly government institutions (Rajwani \& Liedong, 2014; Taillard, 2013). Companies may use several different tactics for influence on government: through the development and cooperation of political action committees (PACs), political lobbying, and engaging in grassroots activism as well as developing relationships with key segments of the public (Doh et al., 2012). While there is some research that indicates CPA can have conditional effects on a firm's efficiency (Hadani, Bonardi, \& Dahan, 2017), the impact and indicated results should be considered for further study in future research.

Primarily, CPA is recognized as a non-market strategy that 'attempts to shape government policy in ways favorable to the firm' (Hillman, Keim, \& Schuler, 2004, p.838). When used as a communication strategy, CPA is recognized as a corporate information-related strategy, which aims 'to affect public policy by providing policymakers specific information about preferences for policy or policy positions and may involve providing information on the costs and benefits of different issue outcomes' (Hillman \& Hitt, 1999, p.834). The variety of CPA activities, and strategic approaches are wide and diverse, and could be recognized in the form of electoral campaigns, policy analysis and development, law and regulation contributions, expert involvement, or even entrance in foreign policy (Mitrovic, 2017a, pp.31-105). The relationship between nonmarket influence and direct market expansion, or overlap between market and non-market strategies, can be found in the influential use of CPA on a government's foreign policy (Mitrovic, 2017b). It is an observable fact that many companies contribute to social wide welfare, especially if they are considered to be 'corporate citizens' (Matten \& Crane, 2005; Moon, Crane, \& Matten, 2005; Wood \& Logsdon, 2008; Taillard, 2012). This form of corporate activity has previously, and at the present, taken place in political circles as social and policy engagement (Alzola, 2013). The use of CPR by companies, including corporate philanthropy as per Hadani \& 
Coombes (2015), has a strongly synergistic connection when used in conjunction with CPA which gives support to a firm's market results. Besides philanthropy, CPR also expresses the ethical, legal, and fair conditions for all stakeholders of a business. When corporations apply CPR tactics to politics as a form of "political CPR", it functions as a strategic corporate-centric view utilizing society-centric efforts and messages to build sociological value within a productive corporate growth strategy (Morsing \& Roepstorff, 2015). In regard to governmental relations, a corporation's use of CPR has a mission to develop trust between the company and government (Lock \& Seele, 2016). Moreover, CPR activities send a signal to a company's institutional environment that it stands apart from its competition (Werner, 2011), but even if we consider this approach as political CPR with the aim to affect policy outcomes by influencing political constituencies the results of the influence are modest (Fooks \& Gilmore, 2013). Specifically, government institutions, lawmakers, and regulatory proposition agencies could not recognize the ability or skills of firms in policy issues, because they are not exclusively presented, or expressed; although shaping policy through active political manipulation has had greater results than developing goodwill among policymakers (Taillard, 2012).

According to Liedong et al. (Liedong, Ghobadian, Rajwani, \& O'Regan, 2015), the 'CPR contains two dimensions of trustbenevolence, and integrity-but does not convince on the third dimension-policy ability/skill. Similarly, CPA contains two dimensions of trust-integrity and policy ability/skill — but is not perceived as a benevolent activity. Consequently, CPR and CPA separately create moderate trust, with the former only granting access to policymakers, and the latter influencing only narrow and low salience policy issues.

Combining both overcomes the limitations of each' (Liedong et.al, 2015, pp.13-14). Regarding all the above, it could be concluded that CPA and CPR have a supporting influence on company strength. This is particularly pronounced in conditions where the corporation is operating in conditions of an externally directed crisis, such as the global economic crisis (Ciutacu, Chivu, \& Iorgulescu, 2009). The combination of the influence of CPA and CSR is particularly reflected in the corporation's activities on specific social issues of general importance, such as environmental relations or 'green culture' (Pham, Phan, Tučková, Vo, \& Nguyen, 2018). It is also possible to observe the interaction of $\mathrm{CPA}$ and CSR through the general impact of commercial and tourism developments on the local community. In this case, the local community is a generator of positive odium, thus creating an environment of support from the local population due to the positive economic and brand effects (Milićević, Podovac, \& Đorđević, 2020). The synergy of CPA and CPR could be recognized in deliberative lobbying strategy (Lock \& Seele, 2016) which compiles both activities in a manner of non-market communications approach, with favorable market and policy results.

Furthermore, this implies that the use of CPA and CPR together complements each other in the creation of strong trust between companies and the policy-makers. Of course, this position enables a company to influence on broad and relevant policy issues. This elaborated role and interaction between CPA and CPR in strategic support of a corporation, suggests the following hypothesis:

$A$ systematic and organized approach to the $C P A$ and CPR actions of a corporation create a more favorable operating environment and improved overall business stability.

In the present research, which is based on a comparative quality analysis approach, the described synergistic impact of corporate CPR and CPA on sustainable brand strength is profiled upon several variables generated from the described literature, which demonstrate great potential for positive results.

\section{Methodology}

The methodology of Comparative Quality Analysis (CQA) has been characterized as a modern way to conduct social science research that combines the strengths of traditional quantitative and qualitative methods. It was first presented in the work of Ragin, Mayer, and Drass (1984), Ragin's continued work then fine-tuned the methods of comparative qualitative analysis (Ragin, 1987, 2000, 2008, 2009), and has had the contributions elaborated in further work by Rihoux and Ragin (2009). The use of multi-value comparative quality analysis (mvCQA), which is one of the versions of comparative quality analysis (CQA), aims to compare cases systematically while still preserving a strong focus on individual cases (Ragin 1987; Rihoux \& 
Ragin 2009). The goal of most CQA is thus to explain all cases as comprehensively as possible by taking into account a set of explanatory factors and their complex combinations.

In general, the case orientation of CQA fits well with the wide spectra of social science research. Most of them inquire about the factors causing a given phenomenon, such as law-making outputs (Christmann \& Danaci, 2012), government spending (Vis, 2011), coalition formation and policy change (Fischer 2014), or the success of policy projects (Ney \& Verweij, 2014). Some of the research considers welfare states (Avdagic, 2010), social movements (Wright, \& Schaffer-Boudet, 2012), labour markets (Dixon, Roscigno, \& Hodson 2004), and corporate governance (Bell, Filatotchev, \& Aguilera, 2014). The following research implemented mvCQA and considers the usage of multi-value variables (Cronquist \& BergSchlosser, 2009, pp.69-85). This method includes a review of variable structure, with the purpose of preventing information loss, which is considered a large number of contradictory configurations. Namely, the loss of some values is possible in the case of basic CQA, or Crisp-set Comparative Quality analysis (csCQA) (Rihoux \& De Meur, 2009, pp.33-67) because it considers metalogic created notation (Cronquist \& Berg-Schlosser, 2009). In general, mvCQA is more suitable for value comparative analysis. The mvCQA was developed to meet limitations of csCQA and prevent simplifies dichotomous approach in multivalued, aggregated variable usage. The following research has used software application TOSMANA 1.54 (Tosmana, 2017), which is most appropriate for mvCQA cases.

\subsection{Variables setting}

Besides the differences in social and political impacts of various industries, the research literature considers absolute values of strengthening capacities of the ten highest ranked CPR companies, indexing in 2017 by the Reputation Institute. In variable settings, the following variables were defined:

- CPR retrieved from '2017 Global CPR RepTrak 100: Most Socially Reputable Companies', an annual report of Reputation Institute (CPR, 2017);

- CPA, which are a preset number of CPA offices engaged for presenting of companies interests in USA and EU. Data were delivered by databases analysis of the Center for Responsive Politics (CRP, 2017) and Transparency register of the EU (TR-Transparency register, 2017);

- CPAIN present a total of financial spending on CPA in millions of US dollars. Data were delivered upon databases analysis of the Center for Responsive Politics (CRP, 2017) and Transparency register of EU (Transparency register, 2017);

- BFG retrieved from the 'Global 500/2017The annual report on the world's most valuable brands' of Brand Finance (BFG, 2017);

- FORB retrieved from a database of Internet edition of Forbes (FORB-Forbes, 2017);

- GRT retrieved from 'Global RepTrak 100 Report 2017' of Reputation Institute (GRT-Reputation Institute, 2017). For Lego Systems (Lego, 2016) and Bosh (Bosch, 2016), there aren't records in Forbes' summary, and data were taken from companies annual reports for 2016, with consideration of projection for stable financial flow and exception of financial crises in both companies' through 2017;

- PROF, upon Forbes' The World's Biggest Public register (FORB-Forbes, 2017).

\subsection{Logic frame and variable set's interaction}

In research, the foundry-based theory indicates sets of variables that are observed.

Case descriptions indicate that observed subjects are presented in a random set of companies (COM), chosen by a rank of highestindexed CPR activities in 2017: LEGO, Microsoft, Google, Walt Disney, BMW, Intel, Cisco, Bosch, Rolls Royce, and ColgatePalmolive. For the purpose of validation of logic ('low-high'), some original values of variables are marked with '-' on purpose to meet the necessity of value unification and merger of calculation in a logic frame of a difference of variable expression. Namely, the variables for, BFG, FORB, and GRT scaling numbers are marked with '-' on purpose to follow the logic condition that lowest values amplify criteria closes to a dedicated logic system of values. In this particular research, mvCQA allows that multinomial categorical data could be used (from 0 to 9). As a result of this analysis, the indicators of numeric values are set by logic criteria that lowest ranged company has the lowest influence thought $\mathrm{CPR}$ and $\mathrm{CPA}$ on policy 
higher than ' 0 ' in either CPR or CPA have a positive score in the final result. In addition, these companies are the same companies which are successful, proactive, and profitable independently, holding constant variables related to the type of industry, market, or nature of the business. The exception to this is ColgatePalmolive, with ' 0 ' in CPR and CPA variables, which has positive results in profits. The case of Rolls Royce is clear: ' 0 ' marks for CPR and CPA indicate the presence of an unsuccessful business strategy, profit failure, and strategic brand problems.

\section{Results and discussion}

The outcomes that are produced by TOSMANA in the mvCQA calculation processed and generated from databases indicate the following characteristic findings:

- The most successful company in the presented case is Google, with a significant and dominant high presence in CPR and CPA, but also in all other case covered issues (equation 1). The synergy of CPR and CPA influence could be an indicator for a balanced business strategy approach, which has positive results in all other variables, sets, and areas. The conclusion is that strategic orientation for the balanced development of CPR and CPA is related to overall brand strength and profit effects.

- LEGO has the biggest absolute value of CPR variable index, but still, their profit is an area of '2' (equation 9). Indicators of actual weakness could be recognized in extreme low CPA presence and investments in CPA engagement. In addition, the profit result has been analyzed in the scope of market characteristics and specification of the industry to which LEGO belongs, or that PROF results could not be linearly recognized. Of course, further analysis of variable interaction and the gradient influence could be made in some further research.

- In the most inverse position to the results is Colgate-Palmolive (equation 7). Namely, extreme low absolute involvement in CPR and CPA in the observed case group still got modest, but significant profit. Moreover, Colgate-Palmolive is in a higher profit position than Bosch (equation 8). It is noticeable that Bosch has higher CPR and CPA presence, as well as significantly higher positions in global brand strength (BFG, FORB, and GRT) than Colgate-Palmolive, but still lower absolute profit result. The reason for that could be found in different industries, the nature of brands, and marketing approach. In conclusion, ColgatePalmolive and Bosch deserved to be analyzed as separated cases, in order to deliver findings for the improvement of an overall corporate strategy.

Regarding the results testing the hypothesis, it is concluded that: $C P R$ and $C P A$ have a synergistic and supporting role in the overall communication strategy of the company.

Both of these could significantly support the comparative performance of a company, taking into account the necessity for specifying the unique characteristics for each market, policy environment, industry, and the company's strategic culture and goals.

The findings indicate that the hypothesis is confirmed, with the condition of separating industry niches. Also, the findings specify that a synergistic approach in different markets (US and EU) contribute to the maximization of all effects related to the overall corporate success.

\section{Conclusion}

The synergistic actions of corporate CPR and CPA strategies have a significant positive influence on financial and operational business results. The planning process of $\mathrm{CPR}$ and $\mathrm{CPA}$ should incorporate characteristics of company and industry, policy arena, cultural marketing environment, projected company aims, and goals.

An insufficiently expressed orientation for the planning and implementation of CPR and CPA could be indicators that a company will fail to live up to its potential via brand and marketing capacities. In addition, brand strength is conducted with both strategic communication activities, CPR and CPA. Namely, through CPR and CPA, public recognition of the company through policy actions as a socially responsible, credible, proactive, and accountable corporate "citizen". The planning and implementation of CPR and CPA have to be conducted with the strategic planning process, modelling by practicebased and aim orientated models. Research 
indicates that most the effective brands which have significant profit effects have a balanced approach to the CPR and CPA.sm

\section{References}

Alzola, M. (2013). Corporate Dystopia. Business \& Society, 52(3), 388-426.

https://doi.org/10.1177/0007650312474952

Avdagic, S. (2010). When Are Concerted Reforms Feasible? Explaining the Emergence of Social Pacts in Western Europe. Comparative Political Studies, 43(5), 628-657.

https://doi.org/10.1177/0010414009356178

Baron, D. P. (1995). Integrated Strategy: Market and Nonmarket Components. California Management Review, 37(2), 47-65. https://doi.org/10.2307/41165788

Bell, R. G., Filatotchev, I., \& Aguilera, R. V. (2014). Corporate Governance and Investors' Perceptions of Foreign IPO Value: An Institutional Perspective. Academy of Management Journal, 57(1), 301-320. https://doi.org/10.5465/amj.2011.0146

Bernays, E. (1928). Propaganda. New York: Horace Liveright.

Bernays, E. (1951). Public opinion. New Hampshire: Rumford Press.

BFG - Brand Finance. (2017). Global 500-2017; The annual report on the world's most valuable brands. Retrieved June 20, 2019 from www.brandfinance.com.

Boddewyn, J. J. (2003). Understanding and Advancing the Concept of 'Nonmarket. Business \& Society, 42(3), 297-327. https://doi.org/10.1177/0007650303257504

Bonardi, J.-P., Holburn, G. L. F., \& Bergh, R. G. V. (2006). Nonmarket Strategy Performance: Evidence From U.s. Electric Utilities. Academy of Management Proceedings, 2006(1). https://doi.org/10.5465/ambpp.2006.22896791

Bosch (2016). Bosch Annual Report 2016. Retrieved June 20, 2019 from www.bosch.com.

Christmann, A., Danaci, D. (2012). Direct democracy and minority rights: Direct and indirect effects on religious minorities in Switzerland. Politics and Religion 5(1), 133-160. https://doi.org/10.1017/S1755048311000666

Ciutacu, C., Chivu, L., \& lorgulescu, R. (2009). The global financial crisis: management of deficits and debts. Amfiteatru Economic Journal, 11(Special Number 3), 735-750.

CPR - Reputation Institute. (2017). 2017 Global CPR RepTrak 100: Most Socially Reputable Companies. Retrieved June 25, 2019 from https://www.rankingthebrands.com/PDF/Global\%20CP R\%20RepTrak\%20100\%202017,\%20Reputation\%20In stitute.pdf

Cronquist, L. \& Berg-Schlosser, D. (2009). Multi-Values CQA (mvCQA). In: Rihoux, B., Ragin, C., (ed.) Configurational Comparative Methods: Qualitative Comparative Analysis (CQA) and Related Techniques. London: Sage, 69-85.

CRP- Center for Responsive Politics. (2017). Report corporative responsibility. Retrieved June 25, 2019 from https://www.opensecrets.org/lobby/
Dixon, M., Roscigno, V. \& Hodson, R. (2004). Unions, Solidarity, and Striking. Social Forces, 83(1), 3-33. https://doi.org/10.1353/sof.2004.0107

Doh, J. P., Lawton, T. C., \& Rajwani, T. (2012). Advancing Nonmarket Strategy Research: Institutional Perspectives in a Changing World. Academy of Management Perspectives, 26(3), 22-39. https://doi.org/10.5465/amp.2012.0041

Donaldson, T., \& Preston, L. E. (1995). The Stakeholder Theory of the Corporation: Concepts, Evidence, and Implications. Academy of Management Review, 20(1), 65-91. https://doi.org/10.5465/amr.1995.9503271992

Fischer, M. (2014). Coalition structures and policy change in a consensus democracy. The Policy Studies Journal 42(3), 344-366. https://doi.org/10.1111/psj.12064

Fooks, G. J., \& Gilmore, A. B. (2013). Corporate Philanthropy, Political Influence, and Health Policy. PLOS ONE, 8(11). https://doi.org/10.1371/journal.pone.0080864

FORB-Forbes. (2017). The World's Biggest Public register. Retrieved June 10, 2019 from https://www.forbes.com/global2000/list/\#tab:overall.

GRT-Reputation Institute. (2017). Global RepTrak 100 Report 2017. https://www.rankingthebrands.com/PDF/Global\%20Rep Trak\%20100\%20Report\%202017,\%20Reputation\%20I nstitute.pdf

Hadani, M., Bonardi, JP. \& Dahan, N. (2017). Corporate political activity, public policy uncertainty, and firm outcomes: A meta-analysis. Strategic Organization, 15(3), 338-366. https://doi.org/10.1177/1476127016651001

Hadani, M., Coombes, S. (2015). Complementary Relationships Between Corporate Philanthropy and Corporate Political Activity: An Exploratory Study of Political Marketplace Contingencies. Business \& Society, 54(6), 859-881. https://doi.org/10.1177/0007650312463691

Hillman, A. J., \& Hitt, M. A. (1999). Corporate political strategy formulation: A model of approach, participation, and strategy decisions. Academy of Management Review, 24(4), 825-842. https://doi.org/10.5465/amr.1999.2553256

Hillman, A. J., Keim, G. D., \& Schuler, D. (2004). Corporate political activity: A review and research agenda. Journal of Management, 30(6), 837-857. https://doi.org/10.1016/j.jm.2004.06.003

Lawton, T., Mcguire, S., \& Rajwani, T. (2012). Corporate Political Activity: A Literature Review and Research Agenda. International Journal of Management Reviews, 15(1), 86-105. https://doi.org/10.1111/j.1468-2370.2012.00337.x

Lego. (2016). The LEGO Group Annual Report 2016. Retrieved June 5, 2019 from www.LEGO.com

Pham, N., Phan, Q., Tučková, Z., Vo, N., Nguyen, L..L. (2018). Enhancing the organizational citizenship behavior for the environment: the roles of green training and organizational culture, Management \& Marketing. Challenges for the Knowledge Society, 13(4), 11741189. https://doi.org/10.2478/mmcks-2018-0030 
Liedong TA, Ghobadian A, Rajwani T, \& O'Regan N. (2015). Toward a View of Complementarity: Trust and Policy Influence Effects of Corporate Social Responsibility and Corporate Political Activity. Group \& Organization Management, 40(3), 405-427. https://doi.org/10.1177/1059601114560064

Lock, I. \& Seele, P. (2016). Deliberative Lobbying? Toward a Non-contradiction of Corporate Political Activities and Corporate Social Responsibility? Journal of Management Inquiry, 25(4), 415-430. https://doi.org/10.1177/1056492616640379

Matten, D., \& Crane, A. (2005). Corporate Citizenship: Toward an Extended Theoretical Conceptualization. Academy of Management Review, 30(1), 166-179. https://doi.org/10.5465/amr.2005.15281448

Milićević, S., Podovac, M., \& Đorđević, N. (2020). Attitudes of the local population about tourist events - the case study of the Vrnjačka Carnival. Ekonomika, 66(2), 7591. https://doi.org/10.5937/ekonomika2002075M

Mitrovic, M. (2017a). Strategic lobbying: Practice and models for the development of influence communication strategy. Kragujevac: Koraci.

Mitrovic, M. (2017b). The Potential Influence of Interest Groups on the US Foreign Policy - a Case of 'Kosovo'. Matica Srpska Social Sciences Quarterly, 163 (3/2017): 413-428. https://doi.org/10.2298/ZMSDN1763413M

Mitrović, M. (2019). Strategic communication concept implemented through the corporate political activities suggested strategy modeling. Strategic Management, 24(4), 13-20. https://doi.org/10.5937/StraMan1904013M

Moon, J., Crane, A., \& Matten, D. (2005). Can Corporations be Citizens? Corporate Citizenship as a Metaphor for Business Participation in Society. Business Ethics Quarterly, 15(3), 429-453. https://doi.org/10.5840/beq200515329

Morsing, M., Roepstorff, A., (2015). CPR as Corporate Political Activity: Observations on IKEA's CPR IdentityImage Dynamics. Journal of Business Ethics 128(2), 395-409. https://doi.org/10.1007/s10551-014-2091-1

Ney, S., \& Verweij, M. (2014). Exploring the Contributions of Cultural Theory for Improving Public Deliberation about Complex Policy Problems. Policy Studies Journal, 42(4), 620-643. https://doi.org/10.1111/psj.12078

Oliver, S., (2007). Public Relations Strategy. London: Kogan Page.

Rajwani, T., \& Liedong, T. A. (2014). Political Activity and Firm Performance within Nonmarket Research: $A$ Review and International Comparative Assessment. SSRN Electronic Journal. https://doi.org/10.2139/ssrn.2532382

Ragin, C. (1987). The Comparative Method: Moving beyond Qualitative and Quantitative Strategies. Berkeley: University of California Press.

Ragin, C. (2000). Fuzzy-set Social Science. Chicago: University of Chicago Press.

Ragin, C. (2008). Redesigning Social Inquiry: Fuzzy Sets and Beyond. Chicago: University of Chicago Press. https://doi.org/10.7208/chicago/9780226702797.001.00 $\underline{01}$
Ragin, C. (2009). Qualitative Comparative analysis Using Fuzzy Sets (fsCQA). In Rihoux, B., Ragin, C., (ed.) Configurational Comparative Methods: Qualitative Comparative Analysis (CQA) and Related Techniques. London: Sage, 87-121. https://doi.org/10.4135/9781452226569.n5

Ragin, C., Mayer, S. \& Drass, K. (1984). Assessing Discrimination: A Boolean Approach. American Sociological Review, 49(2), 221-34. https://doi.org/10.2307/2095572

Rihoux, B., De Meur, G. (2009). Crisp-set Qualitative Comparative Analysis (csCQA). In: Rihoux, B., Ragin, C., (ed.) Configurational Comparative Methods: Qualitative Comparative Analysis (CQA) and Related Techniques. London: Sage, 33-68. https://doi.org/10.4135/9781452226569.n3

Rihoux, B., \& Ragin, C. (2009). Configurational Comparative Methods: Qualitative Comparative Analysis (QCA) and Related Techniques. SAGE Publications, Inc. https://doi.org/10.4135/9781452226569

Schuler, D. A., Rehbein, K., \& Cramer, R. D. (2002). Pursuing Strategic Advantage Through Political Means: A Multivariate Approach. Academy of Management Journal, 45(4), 659-672. https://doi.org/10.2307/3069303

Taillard, M. (2012). Economics and modern warfare. London: Palgrave MacMillan. https://doi.org/10.1057/9781137282255

Taillard, M. (2013). Psychology and modern warfare. London: Palgrave MacMillan. https://doi.org/10.1057/9781137347329

Taillard, M. (2014). Analytics and modern warfare. London: Palgrave MacMillan. https://doi.org/10.1057/9781137407870

Tosmana (2017). Tosmana 1.54. Retrieved June 7, 2019 from http://www.tosmana.net

TR-Transparency register (2017). Transparency register of European Commission of EU. Retrieved June 7, 2019 from

http://ec.europa.eu/transparencyregister/public/consulta tion/

Vis, B. (2011). Under which conditions does spending on active labour market policies increase? An fsCQA analysis of 53 governments between 1985 and 2003 European Political Science Review, 3(2), 229-252. https://doi.org/10.1017/S1755773910000378

Werner, T. (2011). Do private policies create a new politics? Corporate social responsibility, information, \& access. Austin: University of Texas.

Wicks, A. C., Gilbert, D. R., \& Freeman, R. E. (1994). A Feminist Reinterpretation of The Stakeholder Concept. Business Ethics Quarterly, 4(4), 475-497. https://doi.org/10.2307/3857345

Wood, D. J., \& Logsdon, J. M. (2008). Business Citizenship as Metaphor and Reality. Business Ethics Quarterly, 18(1), 51-59. https://doi.org/10.5840/beq20081815

Wright, R. A., \& Boudet, H. S. (2012). To Act or Not to Act: Context, Capability, and Community Response to Environmental Risk. American Journal of Sociology, 118(3), 728-777. https://doi.org/10.1086/667719 


\section{$\triangle$ Correspondence}

\section{Miroslav Mitrović}

Strategic Research Institute

Neznanog junaka 38, 11000 Belgrade, Serbia

E-mail: mitrovicmm@gmail.com 